\title{
Homocysteine levels and bad obstetric outcome among female operating room personnel occupationally exposed to nitrous oxide
}

\author{
Uzun S, Saricaoglu F, Ayhan B, Topatan B, Akinci SB, Aypar U \\ Hacettepe University, Faculty of Medicine, Department of Anaesthesiology and Reanimation, Sihhiye, Ankara, \\ Turkey.sennuruzun1@gmail.com
}

\begin{abstract}
It is known that nitrous oxide $\left(\mathrm{N}_{2} \mathrm{O}\right)$ inactivates vitamin $\mathrm{B}_{12}$ and causes hyperhomocysteinemia. The personnel working at the operating theatres are repeatedly exposed to $\mathrm{N}_{2} \mathrm{O}$ in the ambient air. This prompted us to investigate the biochemical indices of vitamin $\mathrm{B}_{12}$ metabolic status among female personnel working under various levels of $\mathrm{N}_{2} \mathrm{O}$ exposure. In this study, the homocysteine and folic acid levels were assessed and bad obstetric outcome was questioned. Sixty operating theatre female personnel were examined. Vitamin $\mathrm{B}_{12}$ and folic acid, total homocysteine level, anticardiolipin IgM, IgG, antiphospholipid IgM, IgG levels were measured in serum. A questionnaire inquiring about obstetric history was given. The serum concentration of folic acid was $10 \pm 3.3 \mathrm{nmol}_{\text {liter }}^{-1}$. The vitamin $\mathrm{B}_{12}$ level was $332 \pm 134 \mathrm{pmol}$ liter ${ }^{-1}$, the serum concentration of homocysteine was $9.1 \pm 2.4 \mathrm{nmol}_{\text {liter }}^{-1}$ and all were within normal ranges. There was no difference regarding homocysteine, folic acid, vitamin $B_{12}$ levels and the obstetric history between the subjects who had abortus history and the subjects who had not abortus history. Exposure to $\mathrm{N}_{2} \mathrm{O}$ in healthcare workers was not associated with alterations of homocysteine, folic acid status and bad obstetric outcome (Tab. 4, Ref. 18). Text in PDF www.elis.sk. Key words: operating rooms, drug contamination, nitrous oxide, pregnancy outcome.
\end{abstract}

Although several efforts have been made to minimize the exposure to waste anaesthetic gases by improving the working environment, contamination of operating theatre air is still unavoidable, whenever anaesthetic agents were given by inhalation (1).

Several independent groups suggested that there is a health risk associated with chronic occupational exposure to waste anaesthetic gases. These studies mainly focused on spontaneous foetal abortions leading to the assumption that genetic damage of foetus occurs during pregnancy (2-5). Nitrous oxide is an inhalation anaesthetic and analgesic, which is widely used in operating theatres. Several epidemiological studies have shown associations between occupational exposure to this agent and adverse pregnancy outcomes (6). Nitrous oxide acts by oxidizing vitamine $\mathrm{B}_{12}$ from the active cobalamin (cobI) to the inactive cobalamine (cobIII) (7).

Healthcare workers who are active in operating theatres are repeatedly exposed to $\mathrm{N}_{2} \mathrm{O}$ in the ambient air (8). Although deleterious effects of $\mathrm{N}_{2} \mathrm{O}$ were reported in patients undergoing anaesthesia, little effort has been directed towards evaluation of the influence of $\mathrm{N}_{2} \mathrm{O}$ on vitamin $\mathrm{B}_{12}$ metabolism in operating personnel.

Hacettepe University, Faculty of Medicine, Department of Anaesthesiology and Reanimation, Sihhiye, Ankara, Turkey

Address for correspondence: S. Uzun, Dr, Hacettepe University Faculty of Medicine, anaesthesiology and Reanimation Department, Sihhiye, 06100 Ankara, Turkey.

Phone: +90.312.3051250, Fax: +90.312.3109600
Interest in the prognostic value of circulating homocysteine concentration continues to grow. There is already a large body of evidence indicating that elevated plasma total homocysteine ( $\mathrm{tHyc})$ (Hyperhomocysteinemia ) may be causally related to risk of coronary, cerebral, peripheral arterial diseases, pregnancy disorders and recurrent pregnancy loss (7, 9-13). Preeclampsia, prematurity, very low birth weight, stillbirths, neural tube defects, and clubfoot were significantly associated with high tHyc levels (11-14).

Homocysteine is a thiol containing amino acid, which is not used in protein synthesis but which is, instead, involved at junction of two major metabolic pathways in human physiology. First, it can be condensed with the amino acid serine in an irreversible sulphuration reaction catalysed by enzyme cystathionine beta synthase in the presence of pyridoxine (vitamin $\mathrm{B}_{6}$ ) to form cystathionine, which is then reduced to form cysteine, which can be excreted. Alternatively, homocysteine can be reversibly methylated to reform the essential amino acid methionine, taking methyl groups from the folic acid pathway in a reaction catalyzed by methionine synthase in the presence of cobalamine (vitamine $\mathrm{B}_{12}$ ), thus allowing the further methylation processes vital to ongoing cellular activity on living organism. It will be seen that, in the absence of or with reduced concentrations of vitamin $\mathrm{B}_{6}$, of vitamin $\mathrm{B}_{12}$ and of folic acid, homocysteine concentrations will rise. Similarly, if the enzymes controlling the metabolism of homocysteine are inactivated or made less efficient, once again homocysteine concentration will increase (7-10).

In this study, we aimed to investigate the correlation between high tHyc levels and bad pregnancy outcome among the female 
operating theatre personnel actively working in the operating theatre.

\section{Methods}

After the institutional ethics committee approval and informed consent from each subject, our study was planned to take place in 60 nurses working in 25 different operating theatres for general anaesthesia and recovery rooms. The operating theatres, in which we conducted the study, are the main operating theatres rooms for extended operations. Isoflurane, sevoflurane, desflurane and nitrous oxide were used for anaesthesia. On an average, $\mathrm{N}_{2} \mathrm{O}$ was used for 10 hours in a day for anaesthesia management. There was an air-change system without air intake in the operating theatres and recovery rooms. Anaesthesiology equipment was a closed breathing systems, and waste anaesthetic gas systems were passive scavenging systems.

In total, 60 female personnel of anaesthesia or surgery working in operating theatres or recovery area were included into the study. Our inclusion criteria were that the personnel worked a minimum of 6 hours daily for at least 3 years in the operating theatre or recovery room. All were asymptomatic with an unremarkable medical history and a normal physical examination. Blood samples were collected at the end of the daily shift. The serum was send to the

Table 1: Follow up Form

\begin{tabular}{|c|c|c|c|}
\hline $\begin{array}{l}\text { Name surname: } \\
\text { Age: }\end{array}$ & & Medical record no: & \\
\hline Gravida: & Parity: & IUeX (after 20 week): & Abortus \\
\hline $\mathrm{D} / \mathrm{C}:$ & Living child: & PPex: & $\begin{array}{l}\text { First } 10 \text { week } \\
\text { 10-20 week }\end{array}$ \\
\hline & & & Not known: \\
\hline
\end{tabular}

\section{Past medical and genetic history}

Deep venous thrombosis (DVT) $\square$

Cardiological disease $\square$

DVT history in family $\square$

Previeous pregnancy PIH (pregnancy induced hypertension)/preeclampsia $\square$

Myocardial Infarction (MI) history before 40 years $\square$

Preview pregnancy gestational diabetes mellitus (DM) $\square$

Pulmonary thromboemboli history $\square$

Bronchial Asthma $\square \quad$ Goitre $\square \quad$ Allergy $\square$

Smoking $\square \quad$ Thromboembolic events $\square \quad$ Alcohol $\square$
Pulmonary thromboembolism $\square$

Surgery $\square$

Diabetus mellitus

Patient's drugs: Other:

General questions

Status in operating room: doctor nurse

Part: anesthesia other

Working hours:

How many years have you been working in the operating room?

How many years have you been married?

How many years have you desired to become pregnant?

Mensturation profile

Partner: Sperm analysis Normal Abnormal

Known disease:

Pregnancy complication

Preterm labour $\square$

Postterm pregnancy $\square$

Early pregnancy loss

First 10 week $\square$

10-20 week

$20<\square$

Fetal growth retardation

SGA (small for gestational age) $\square$

Hypertension $\square$

Type II DM $\square$

Autoimmune disease $\square$

Child with a anomalia $\square$ Previous pregnancy preterm labour $\square$

IUGR (Intrauterine growth retardation) $\square<3$ th percentil $<10$ th percentil

Hyperemesis gravidarum $\square$

Advanced maternal age $\square$

In which part of the pregnancy did you continue to work at the hospital?

1.trimester $\square \quad$ 2.trimester $\square \quad$ 3.trimester $\square$

Birth

Type of birth

Type of birth

Complication related to the fetus

Mortality $\square$

Oligohydramnios $\square \quad$ Polihydramnios $\square$

Rh-Rh isoimmunisation $\square$

Ablatio placenta $\square$

Still birth $\square$

Gestational diabetus mellitus $\square$

Multifetal pregnancy $\square$

PIH-preeclampsia $\square$

Macrosomia $\square$

Intraventricular hemorhage $\square$

Gestational week___ Sex
Gestational week___ Sex

BW

LH $\square$

Retinopathy $\square$

Necrotizing enterokolitis $\square$ 
Biochemistry Laboratory of the University Hospital for determination of the following parameters by electrochemiluminescence immunoassay (ECLIA) procedures: Homocysteine (normal range 5.5-17 nmol liter ${ }^{-1}$ ), vitamin $B_{12}$ (normal range 160-800 pmol liter $^{-1}$ ), folic acid (normal range $3-17$ pmol liter $^{-1}$ ), anticardiolipin IgM, IgG and antiphospholipid IgM and IgG.

A questionnaire inquiring about reproductive history; employment, health problems, medications and lifestyle habits was given to each subject (Tab. 1). We excluded personnel with conditions that affect the determination of their oxidative stress status, such as those taking any chronic medications for autoimmune diseases, liver or pulmonary diseases, acute or chronic inflammation, vitamin supplements, antioxidants and those who smoked or consume alcohol on a regular basis. All the operating theatre female personnel were included into the study as no one was meeting the exclusion criteria.

\section{Statistical analysis}

An exploratory statistics was performed using the Statistical Package for the Social Sciences (SPSS version 11.5). The results were expressed as the mean \pm standard deviation or as the median (25-75 \% confidence intervals) or as frequencies (\%). Kolmogorov-Smirnov test was used to test for normal distribution of the numeric variables. The subjects who had abortus history were compared to the subjects without abortus history regarding categorical variables with Chi-Square test and numerical variables such as age, serum folic acid, vitamin $B_{12}$, homocyteine levels with t-test and anticardiolipin IgM, IgG, antiphospholipid IgM and IgG with the Mann-Whitney $U$ tests, respectively. p values $<0.05$ were considered significant.

\section{Results}

The characteristics of the group is seen in the Table 2. The operating theatre personnel had either 8 hours (35 (58 \%) subjects) or 9 hours (25 (42\%) subjects) working shifts.

Detailed obstetric history of the operating theatre personnel was shown on Table 3. Five (19 \%) subjects out of 26 had early (during the first 10 weeks of gestation) pregnancy loss. One subject $(1.7 \%)$ had two pregnancy losses between 10 and 20 weeks of gestation. Two (8\%) subjects had preterm deliveries. One woman $(1.7 \%)$ had premature rupture of membranes. Five (21\%) women had intrauterine growth retardation. Two women ( $8 \%$ ) were observed to be in advanced maternal age during their pregnancies. There was only one $(1.7 \%)$ multifoetal pregnancy. The first deliveries were vaginal in 12 (50 \%) and caesarean section in the other 12 subjects. The first deliveries of the subjects occurred at $38 \pm 2.5$ weeks of gestation. The mean birth weight of

Table 2. Demographic characteristics of the study subjects.

\begin{tabular}{lc}
\hline Age (years) & $31 \pm 6$ \\
Employment duration (years) & $6.8 \pm 7$ \\
Married & $34(56.7 \%)$ \\
Occupation: physician/nurse/OR technician/nurse anaesthetists & $15 / 29 / 14 / 2$ \\
\hline
\end{tabular}

Table 3. The obstetric history of the operating theatre room personnel. Values are frequency $(\%)$.

\begin{tabular}{lc}
\hline Ever wanted children & $11(18 \%)$ \\
\hline Number of gravida & 5 \\
0 & 5 \\
1 & 13 \\
2 & 5 \\
3 & 2 \\
7 & 3 \\
\hline Number of parity & 15 \\
0 & 9 \\
1 & \\
2 & 18 \\
\hline Number of dilatation and curettage & 6 \\
0 & 2 \\
1 & 3 \\
2 & 14 \\
\hline Number of live births & 9 \\
0 & \\
1 & 24 \\
2 & 2 \\
\hline Number of intrauterine exitus & \\
0 & 21 \\
1 & 1 \\
\hline Number of abortus & 2 \\
\hline In the first 10 gestational weeks & 1 \\
0 & 1 \\
1 & \\
2 & \\
4 & \\
\hline $10-20$ weeks of gestation & \\
\hline
\end{tabular}

Table 4: Laboratory results

\begin{tabular}{|c|c|c|c|}
\hline & $\begin{array}{l}\text { Subjects who } \\
\text { had abortus } \\
(\mathrm{n}=5)\end{array}$ & $\begin{array}{l}\text { Subjects who } \\
\text { had not abortus } \\
(n=55)\end{array}$ & $P$ \\
\hline Homocysteine (nmol liter-1) & $10.69 \pm 3.98$ & $7.95 \pm 1.42$ & 0.09 \\
\hline Folic acid (nmol liter $\left.{ }^{-1}\right)$ & $9.59 \pm 3.75$ & $12.05 \pm 3.98$ & 0.26 \\
\hline Vitamin B12 (pmol liter $\left.{ }^{-1}\right)$ & $369.14 \pm 33.23$ & $371.07 \pm 157.46$ & 0.42 \\
\hline Anticardiolipin IgM, n(\%) & 1 (\% 1.8) & $1(\% 20)$ & 0.101 \\
\hline Anticardiolipin IgG, n(\%) & $1(\%$ 1.8) & $0(\% 0)$ & 0.917 \\
\hline Antiphospholipid IgM, n(\%) & $1(\% 1.8)$ & $0(\% 0)$ & 0.917 \\
\hline Antiphospholipid IgG, n(\%) & $1(\% 1.8)$ & $0(\% 0)$ & 0.917 \\
\hline
\end{tabular}

Values are mean \pm standard deviation (homocysteine, folic acid, vitamin B12) and number (\%)

the first-born newborns were $3071 \pm 636$ grams and seven out of 24 were male. The second deliveries were vaginal in six (60\%) and caesarean section in the other four subjects. The second deliveries of the subjects occurred at $38.4 \pm 1.3$ weeks of gestation and the mean birth weight of the newborns were $3286 \pm 414$ grams (eight out of 10 newborns were male). One subject reported macrosomia of the newborn. None of the subjects reported stillbirths or postpartum neonatal deaths. Complications in the newborn such as intraventricular hemorrhage, retinopathy or necrotizing enterocolitis were not reported. One subject had pulmonary thromboembolism during her last pregnancy. Two (3.3 \%) women had children with anomalies. 
None of the study subjects had cardiac disease, diabetes, alcohol consumption or deep vein thrombosis history. Three subjects had allergies and 44 subjects were non-smokers. One woman had asthma, five had goitre disease who did not need any medication.

The mean \pm SD homocysteine level was $9.1 \pm 2.4$ nmol liter $^{-1}$ (normal range 5.5-17 nmol liter ${ }^{-1}$ ), the mean \pm SD serum concentration of folic acid was $10 \pm 3.3 \mathrm{nmol}$ litre $^{-1}$ (normal range 3-17 pmol liter ${ }^{-1}$ ), the mean $\pm S D$ vitamin $B_{12}$ levels were $332 \pm 134 \mathrm{pmol}$ liter $^{-1}$ (normal range 160-800 pmol liter ${ }^{-1}$ ), and all were within normal limits. There was no difference regarding homocysteine, folic acid, vitamin $B_{12}$ levels and the obstetric history between the subjects who had abortus and the subjects who had not abortus (p>0.05) (Tab. 4).

The serum anticardiolipin IgM and IgG were positive only in two (3.3 \%) and one (1.7 \%) subjects respectively. Antiphospholipid IgM was positive in one (1.7 \%) and antiphospholipid IgG was positive in another (1.7\%) subject (Tab. 4).

\section{Discussion}

Nitrous oxide is widely used in the operating theatres for anaesthesia managements and the staff who work in these theatres are occupationally exposed to this agent. According to the recent well-documented reports, it is well known that $\mathrm{N}_{2} \mathrm{O}$ causes Hyperhomocysteinemia (tHcy) which is a risk factor for bad pregnancy outcome $(2,10,12,15,16)$. We hypothesized that occupational exposure to $\mathrm{N}_{2} \mathrm{O}$ causes tHcy and this is a risk factor for recurrent early pregnancy loss. We wanted to examine the tHyc, vitamin $\mathrm{B}_{12}{ }^{-}$ folic acid levels of our female operating personnel and correlation with bad obstetric outcomes.

There are several reports of hyperhomocystenemia associated with pregnancy disorders and recurrent pregnancy loss (11-14). Krajewski and colleagues (15) reported impaired vitamin $B_{12}$ metabolic status and significantly increased tHcy levels in female nurses with occupational exposure to $\mathrm{N}_{2} \mathrm{O}$. In this study, we examined the relation of tHcy levels with bad obstetrical outcome among the female operating theatre personnel. There isn't a control group because that design was planned to be the second stage in case of significant increases in tHcy levels in our exposed group. Fortunately, all measurements were in normal ranges according to our university laboratory ranges and we have not any significant rate of abortions. Krajewski et al (13) reported lower vitamin $B_{12}$ and higher tHcy levels in their exposed group.

Currently, several randomized, placebo-controlled trials are ongoing and the results should make possible a meaningful assessment of whether lowering homocysteine concentration does indeed reduce the risk of cardiovascular diseases. Vollset et al (11) report that hyperhomocysteinemia may also be an important biological marker for, and possibly even a cause of or a contributor to complications and adverse outcomes of pregnancy. When comparing quartiles of homocysteine concentration measured in 5883 women aged 40-42 years, between 1992-1993 with outcomes and complications of 14492 pregnancies that occurred between 1967 and 1996 in the same women, authors noted an increased risk of preeclampsia, premature delivery, very low birth weight, neural tube defects, and clubfoot. Rowland et al (17) reported that occupational exposure to high levels of $\mathrm{N}_{2} 0$ may adversely affect women's fertility. We did not detect any relation between bad obstetric history and working in the operating theatre probably due to advanced scavenging systems used in our operating theatres.

Despite advanced scavenging systems, the level of pollution in operating theatres depends on multiple factors such as the type of anaesthesiology equipment (closed/open system), the anaesthesiology techniques (high/low flow rate, use of face masks or laryngeal mask airways, use of uncuffed tracheal tubes), and the methods of anaesthetic induction (18). Low-flow anaesthesia should be used whenever possible to decrease the waste anaesthetic gas level in the operating theatres. The sole use of intravenous drugs such as propofol instead of volatile agents would eliminate occupational exposure but may result in environmental pollution by toxic metabolites. In our operating theatres, we have laminar air condition system preventing the circulation of exhausted air into operating theatre (> 15 air changes $\left.\mathrm{h}^{-1}\right)$.

We studied the effect of exposure to waste anaesthetic gases on pregnancy outcome by studying the homocysteine, folic acid, vitamin $\mathrm{B}_{12}$, anticardiolipin and antiphospholipid levels in female personnel working in operating theatre. In conclusion, tHcy, vitamin $B_{12}$ and folic acid levels were within normal range in our operating theatre female staff. There was no difference between female personnel who had abortus and who had not abortus, in respect to blood levels of homocysteine and bad obstetric outcome.

\section{References}

1. American Society of Anesthesiologist Ad Hoc Committee on the Effect of Trace Anesthetics on the health of Operating Room Personel. Occupational disease among operating room personnel: A national study. Anesthesiology 1974; 41 (4): 321-340.

2. Crawford JS, Lewis M. Nitrous oxide in early human pregnancy. Anaesthesia 1986; 41 (9): 900-905.

3. Gauger VT, Voepel-Lewis T, Rubin P, Kostrzewa A, Tait R. A survey of obstetric complications and pregnancy outcomes in paediatric and non paediatric anaesthesiologists. Paediatr Anaesth 2003; 13 (4): 490-495.

4. Allison JL, Schust DJ. Recurrent first trimester pregnancy loss: revised definitions and novel causes. Curr Opin Endocrinol Diabetes Obes 2009; 16 (6): 446-450.

5. Rosenberg PH, Vanttinen H. Occupational hazards to reproduction and health in anaesthetists and pediatricians. Acta Anaesthesiol Scand 1978; 2(3): 202-207.

6. Ahlborg G JR, Axelsson G, Bodin L. Shift work, nitrous oxide expose and subfertility among Swedish midwives. Int J Epidemiol 1996; 25 (4): 783-790.

7. Graham IM, Daly LE, Refsum HM, Robinson K, Brattström LE, Ueland PM et al. Plasma homocysteine as a risk factor for vascular disease. JAMA 1997; 277 (22): 1775-1781.

8. Smith FD. Management of exposure to waste anesthetic gases. AORN J 2010; 91 (4): 482-494. 


\section{$372-376$}

9. Nygard O, Nordrehaug JE, Refsum H, Ueland PM, Farstad M, Volsett SE. Plasma homocysteine levels and mortality in patients with coronary artery disease. N Engl J Med 1997; 377 (4): 230-236.

10. Nunn JF. Clinical aspects of the interaction between nitrous oxide and vitamin B12. Br J Anaesth 1987; 59 (1): 3-13.

11. Vollset SE, Refsum H, Irgens LM, Emblem BM, Tverdal A, Gjessing HK et al. Plasma total homocysteine, pregnancy complications, and adverse pregnancy outcomes: The Hordaland Homocysteine Study. Am J Clin Nutr 2000; 71 (4): 962-968.

12. Walker MC, Smith GN, Perkins SL, Keely EJ, Garner PR. Changes in homocysteine levels during normal pregnancy. Am J Obstet Gynecol 1999; 180 (3): 660-664.

13. Steegers-Theunissen RP, Wathen NC, Eskes TK, van Raaij-Selten B, Chard T. Maternal and fetal levels of methionine and homocysteine in early human pregnancy. Br J Obstet Gynaecol 1997; 104 (1): 20-24.

14. El-Khairy L, Vollset SE, Refsum H, Ueland PM. Plasma total cysteine, pregnancy complications and adverse pregnancy outcomes:
The Hordaland Homocysteine Study. Am J Clin Nutr 2003; 77 (2): 467-472.

15. Krajewski W, Kucharska M, Pilacik B, Fobker M, Stetkiewicz J, Nofer JR et al. Impaired vitamin B12 metabolic status in healthcare workers occupationally exposed to nitrous oxide. Br J Anaesth 2007; 99 (6): 812-818.

16. Öztürk Ö, Karaer S, Uncu D, Efesoy A. Serum homocysteine, folate, and vitamine B12 levels in pregnant and non-pregnant women. Turkiye Klinikleri J Med Sci 2006; 26 (2): 121-125.

17. Rowland AS, Baird DD, Weinberg CR, Shore DL, Shy CM, Wilcox AJ. Reduced fertility among women employed as dental assistants exposed to high levels of nitrous oxide. N Engl J Med 1992; 327 (14): 993-997.

18. Krajewski W, Kucharska M, Wesolowski W, Wronska-Nofer T. Occupational exposure to nitrous oxide: The role of scavenging and ventilation systems in reducing the exposure level in operating rooms. Int J Hyg Environ Health 2007; 210 (2): 133-138. 